\title{
Editorial: Observational Assessments of Glacier Mass Changes at Regional and Global Level
}

\author{
Laura Thomson ${ }^{1 *}$, Fanny Brun ${ }^{2}$, Matthias Braun ${ }^{3}$ and Michael Zemp ${ }^{4}$ \\ ${ }^{1}$ Department of Geography and Planning, Queen's University, Kingston, ON, Canada, ${ }^{2}$ Department of Physical Geography, \\ Université Grenoble Alpes, Saint Martin d'Hères, France, ${ }^{3}$ Department of Geography and Geosciences, Friedrich-Alexander- \\ University of Erlangen-Nuremberg, Erlangen, Germany, ${ }^{4}$ Department of Geography, University of Zurich, Zurich, Switzerland
}

Keywords: glaciers, mass change, climate change, cryosphere, sea-level rise

Editorial on the Research Topic

\section{Observational Assessments of Glacier Mass Changes at Regional and Global Level.}

Glaciers represent a measurable indicator of the spatial and temporal patterns of global climate variability. Those distinct from the Greenland and Antarctic Ice Sheets cover an area of approximately $706,000 \mathrm{~km}^{2}$ globally (RGI Consortium, 2017), with an estimated total volume of $170 \pm 21 \times 10^{3} \mathrm{~km}^{3}$, or $0.43 \pm 0.06 \mathrm{~m}$ of potential sea-level rise equivalent (Huss and Farinotti, 2012). Retreating and thinning glaciers are icons of climate change and affect the local hazard scenario, regional water resources and glacier runoff as well as changes in global sea level.

Techniques for measuring and monitoring changes to glaciers over the last century have expanded from in situ point measurements of snow accumulation and ice ablation to large regional- and globalscale surveys employing remote sensing and modeling approaches, which have shaped our understanding of world-wide glacier changes. Today, the Gravity Recovery and Climate Experiment (GRACE) mission can be used to derive monthly regional mass changes (Wouters et al.) and has proven to be particularly effective in detecting glacier mass changes over regions with extensive ice cover (Alaska, Canadian Arctic, Russian Arctic, Svalbard, Iceland, the Southern Andes, and High Mountain Asia). However, Wouters et al. note that GRACE cannot resolve the signal from peripheral glaciers of the Greenland and Antarctic ice sheets and struggles to detect statistically significant signals in mountain ranges with smaller glacier covers due to weaker signals and relatively greater background noise and uncertainty.

Increasingly, geodetic mass-balance records are filling the spatial-scale gap between coarseresolution gravimetry and point-based glaciological mass-balance records. Advances in digital elevation model creation, automation, and analysis from historic and contemporary sources are driving a notable increase in the availability of geodetic mass-balance records from around the world. Indeed, original works within this Research Topic alone represent 9,908 new geodetic mass balance contributions to the World Glacier Monitoring Service (WGMS) and the IPCC AR6, notably from regions of Greenland (Huber et al.), the European Alps (Davaze et al.), Iceland (Belart et al.), Northern Tien Shan (Kapitsa et al.) and the Patagonian Andes (Falashi et al.), as well as 8,000 updated geodetic records from the Central Andes (Ferri et al.). Advances in digital photogrammetry and improved accuracies in the $3 \mathrm{D}$ alignment of elevation models have rekindled the scientific value inherent to historical maps, aerial photography and declassified spy satellite imagery as exemplified by Falashi et al., Huber et al., Belart et al., and Kapitsa et al. These advances extend the temporal reach 
of geodetic mass-balance estimates, offering new life to early imagery and resulting in notably reduced uncertainties in geodetic mass-balance estimates. However, issues persist in high-elevation, snow-covered regions where low contrast between images results in data voids, leading researchers to devise strategies for void-filling (Huber et al., McNabb et al., 2019; Seehaus et al., 2020).

The global collection of glaciological (in situ) mass-balance records available through WGMS and national monitoring programs provide important cross-validation for gravimetry (Wouters et al.) and geodetic mass-balance methods (Kapitsa et al., Davaze et al., Schuler et al.). Furthermore, these glaciological mass-balance records capture interannual and seasonal mass balance amplitudes and expand our understanding of the regional climatologies (Braithewaite and Hughes) and glacier morphologies (Davaze et al.) responsible for the global and regional variability in glacier response.

While the collection of glaciological mass-balance measurements can be logistically demanding, new potential exists for continuous, remote monitoring of surface massbalance components (accumulation and ablation) given advances in automated field instrumentation and data telemetry. This was demonstrated over a 10-year period (2009-2019) by Fausto et al. using a pressure transducer assembly complemented by sonic ranging systems as part of the Program for Monitoring of the Greenland ice sheet (PROMICE). In the time of COVID-19 and restrictions on field-related travel, the automated measurement and remotedelivery of mass balance measurements and related climate variables is likely to become increasingly popular.

Creative approaches that bring together the more abundant geodetic mass-balance estimates, spanning multiple years, and the relatively small sample of glaciological mass-balance records, providing interannual variability, has also enabled the modeling of annual mass balances for glaciers lacking field observations (e.g. Belart et al.). It was demonstrated by Davaze et al. that annual snowline altitudes in combination with multi-year geodetic records may alternatively provide the annual temporal variability signal required for the estimation of annual mass balances of unmonitored glaciers in the Alps. Aðalgeirsdóttir et al. revealed that the combination of multiple data sources can even support the estimation of mass-balance conditions dating back to the Little Ice Age (estimated as 1890 for Iceland).

Despite these advances, challenges remain regarding the estimation of glacier mass changes. While glaciological mass balances remain an invaluable indicator of temporal variability and important ground-validation for remote sensing and modeling techniques, several studies acknowledge the need for caution using these records. For instance, a slight negative bias has been found to be associated with glaciological records that may be attributed to the relatively shallower slopes of monitored glaciers (Davaze et al.), or due to bias in stake distribution across elevations (Kapitsa et al.). Schuler et al. also highlight the need to extend glaciological mass-balance efforts into under-sampled, often logistically challenging areas to reduce regional biases. In high-latitude and highly glacierized regions, the greater potential for surge dynamics, calving, as well as internal accumulation by melt and refreezing in cold accumulation zones adds uncertainty to mass balance estimates (Schuler et al.). In low-latitude and arid regions, challenges associated with the monitoring of debriscovered ice and rock glaciers persist (Ferri et al.), however the consideration and inclusion of these features in glacier inventories have proven to be particularly valuable in droughtsusceptible regions where ice-rock complexes serve as important water resources (Schaffer et al., 2019).

Independent of technique, the original works presented in this Research Topic indicate mass loss to be the dominant signal observed from glaciers distinct from the ice sheets through the 19th, 20th and early twenty-first centuries. Ice mass changes detected by GRACE over regions with extensive ice coverage confirm widespread losses but cannot detect an acceleration in these losses over the period of record (2002-2016; Wouters et al.). Geodetic mass-balance surveys spanning multiple epochs, including the pre-satellite era, generally demonstrate greater thinning rates toward the end of the 20th century (Falaschi et al., Davaze et al., Aðalgeirsdóttir et al., Braithwaite and Hughes, Schuler et al.), with the exception of northern Tien Shan where very little difference in change rates was observed between 1958-1998 and 1998-2016 periods (Kapitsa et al.). Interestingly, in some instances these studies note a slight decline in thinning rates since 2010 , including in regions of the Patagonian Andes (Falaschi et al.) and Iceland (Belart et al.). The large variability observed in the seasonal and annual massbalance signal (Braithwaite and Hughes; Wouters et al.) highlights the need for persistent efforts at all scales of glacier monitoring and continued "openness and generosity with hardwon data" within the glaciological community (Braithwaite and Hughes).

\section{AUTHOR CONTRIBUTIONS}

The editorial was drafted by LT, with contributions from MZ, $\mathrm{MB}$, and FB. The scope and contents of the editorial were discussed among all authors.

\section{ACKNOWLEDGMENTS}

The present Research Topic is a contribution to the working group on Regional Assessments of Glacier Mass Change (RAGMAC) of the International Association of Cryospheric Sciences (IACS; https://cryosphericsciences.org/activities/wgragmac/). It was enabled by support from the Federal Office of Meteorology and Climatology MeteoSwiss within the framework of the Global Climate Observing System (GCOS) Switzerland for $\mathrm{MZ}$. 


\section{REFERENCES}

Huss, M., and Farinotti, D. (2012). Distributed ice thickness and volume of all glaciers around the globe. J. Geophys. Res. 117, F04010. doi:10.1029/ 2012JF002523

McNabb, R., Nuth, C., Kääb, A., and Girod, L. (2019). Sensitivity of glacier volume change estimation to DEM void interpolation. Cryosphere 13, 895-910. doi:10. 5194/tc-13-895-2019

RGI Consortium (2017). Randolph glacier inventory (v.6.0). A dataset of global glacier outlines. Global land ice measurements from space. doi:10.7265/N5RGI-60

Schaffer, N., MacDonell, S., Réveillet, M., Yáñez, E., and Valois, R. (2019). Rock glaciers as a water resource in a changing climate in the semiarid Chilean Andes. Reg. Environ. Change 19, 1263. doi:10.1007/s10113-018-01459-3
Seehaus, T., Morgenshtern, V. I., Hübner, F., Bänsch, E., and Braun, M. H. (2020). Novel techniques for void filling in glacier elevation change data sets. Rem. Sens. 12, 3917. doi: $10.3390 / \mathrm{rs} 12233917$

Conflict of Interest: The authors declare that the research was conducted in the absence of any commercial or financial relationships that could be construed as a potential conflict of interest.

Copyright (C) 2021 Thomson, Brun, Braun and Zemp. This is an open-access article distributed under the terms of the Creative Commons Attribution License (CC BY). The use, distribution or reproduction in other forums is permitted, provided the original author(s) and the copyright owner(s) are credited and that the original publication in this journal is cited, in accordance with accepted academic practice. No use, distribution or reproduction is permitted which does not comply with these terms. 